\title{
KARAKTERISTIK DAN PERILAKU PENGUNJUNG AGROWISATA KAMPUNG PASIRANGLING
}

\section{VISITORS CHARACTERISTICS AND BEHAVIOR OF AGROWISATA KAMPUNG PASIRANGLING}

\author{
Elly Rasmikayati ${ }^{1}$, Tuti Karyani ${ }^{1}$, Dika Supyandi ${ }^{1}$, Fellingga Cahayu Garwa \\ Widadari Budoyo ${ }^{1}$, Bobby Rachmat Saefudin*2 \\ ${ }^{1}$ Fakultas Pertanian, Universitas Padjadjaran, Jl. Ry Bandung-Sumedang KM.21 Jatinangor, 45363 \\ ${ }^{2}$ Fakultas Pertanian, Ma'soem University, Jl. Raya Cipacing No. 22 Jatinangor, 45363 \\ *E-mail: bobbyrachmat@masoemuniversity.ac.id \\ (Diterima 8-1-2021; Disetujui 18-1-2021)
}

\begin{abstract}
ABSTRAK
Kawasan agrowisata Kampung Pasirangling memiliki daya tarik agrowisata tersendiri bagi para pengujungnya seperti agrowisata pupuk feses sapi, biji kopi kemasan, permen karamel, dan minuman honje. Tujuan dari penelitian ini adalah mendeskripsikan karakteristik pengunjung dan perilaku berkunjung dari pengunjung agrowisata Kampung Pasirangling. Metode penelitian yang digunakan adalah metode penelitian survei kepada 15 pengunjung dan wawancara mendalam dengan key informan. Hasil penelitian menunjukkan bahwa karakteristik pengunjung agrowisata Kampung Pasirangling didominasi oleh remaja laki-laki dan perempuan dalam rentang usia 17-25 tahun yang sebagian besarnya merupakan mahasiswa/i perguruan tinggi dari luar Kabupaten Bandung Barat. Dari segi perilaku berkunjung, pengunjung paling banyak memperoleh informasi mengenai Kampung Pasirangling dari teman lalu pengunjung yang merasa puas mempromosikannya kepada teman-temannya yang lain lalu bersama-sama melakukan kunjungan, sehingga kebanyakan dari mereka sudah pernah berkunjung sebelumnya. Mayoritas pengunjung melakukan kunjungan untuk kegiatan yang berkaitan dengan wisata alam terutama berkemah. Ada juga yang bertujuan untuk pendidikan agrowisata seperti agrowisata hutan lindung, pupuk feses sapi dan pohon tegakan namun persentasenya masih kecil.
\end{abstract}

Kata kunci: karakteristik pengunjung, perilaku berkunjung, agrowisata, Kampung Pasirangling

\section{ABSTRACT}

Kampung Pasirangling agro-tourism area has its own agro-tourism attraction for its visitors, such as cow fecal fertilizer agro-tourism, packaged coffee beans, caramel candy, and honje drinks. The purpose of this study was to describe the characteristics of the visitors and the visiting behavior of the visitors of the Kampung Pasirangling agro-tourism. The research method used is a survey research method to 15 visitors and in-depth interviews with key informants. The results showed that the characteristics of visitors in Kampung Pasirangling agro-tourism were dominated by boys and girls in the age range 17-25 years, most of whom were college students from outside West Bandung Regency. In terms of visiting behavior, visitors get the most information about Kampung Pasirangling from friends and then visitors who are satisfied to promote it to other friends then together make visits so most of them have visited before. The majority of visitors visit for activities related to nature tourism, especially camping. There are also those that aim at agro-tourism education such as protected forest agro-tourism, cow feces fertilizer and tree stands, but the percentage is still small.

Keywords: visitor characteristics, visiting behavior, agro-tourism, Pasirangling Village 


\section{PENDAHULUAN}

Jawa Barat merupakan salah satu provinsi yang menjadi tujuan wisatawan untuk berkunjung. Pada tahun 2018, Jawa Barat berada pada peringkat ke-2 setelah Jawa Timur dalam banyaknya sebaran jumlah perjalanan yang dijadikan tujuan oleh wisatawan nusantara sesuai data pada Tabel 1.

Tabel 1. Persentase Perjalanan Wisatawan Nusantara (Wisnus) Menurut Provinsi Tujuan Tahun 2018

\begin{tabular}{clc}
\hline & Provinsi Tujuan & Proporsi Wisnus (\%) \\
\hline 1. & Sumatera Barat & 2,46 \\
2. & Bali & 2,60 \\
3. & Sulawesi Selatan & 3,32 \\
4. & Banten & 3,41 \\
5. & Sumatera Utara & 3,82 \\
6. & DI Yogyakarta & 4,88 \\
7. & DKI Jakarta & 5,64 \\
8. & Jawa Tengah & 14,92 \\
9. & Jawa Barat & 17,37 \\
10. & Jawa Timur & 17,96 \\
\hline Suber
\end{tabular}

Sumber: BPS (Diolah, 2020)

Banyaknya kunjungan wisatawan ke lokasi wisata didukung oleh faktorfaktor tertentu. Menurut kajian Rudita et al (2012), faktor-faktor yang mempengaruhi ketertarikan wisatawan untuk berkunjung adalah pelayanan, jenis rekreasi wisata, fasilitas yang ditawarkan, fasilitas transportasi menuju lokasi wisata, dan promosi. Salah satu faktor yang mempengaruhi kunjungan wisatawan ke Jawa Barat dikarenakan jenis rekreasi wisatanya yang beraneka ragam dimana terdapat 496 jenis objek wisata yang ditawarkan, antara lain adalah wisata alam, wisata budaya, hingga wisata khusus (Sukriah, 2014).

Kawasan Bandung Raya merupakan salah satu kota di Indonesia yang kegiatan pariwisatanya tidak pernah sepi kunjungan. Hal tersebut dikarenakan faktor cuaca yang sejuk dan terdapat banyak pemandangan alam yang indah, selain itu Bandung memiliki banyak macam hasil kerajinan yang unik dan menarik, wisata kuliner yang beragam, dan lain sebagainya (Machdalena et al, 2018). Banyaknya destinasi wisata yang berada di kota Bandung menjadikan konsumen untuk lebih spesifik menentukan objek wisata mana yang ingin mereka kunjungi.

Salah satu kabupaten yang banyak dikunjungi karena objek wisatanya adalah Kabupaten Bandung Barat. Pada tahun 2015, Dinas Kebudayaan dan Pariwisata Provinsi Jawa Barat menyatakan bahwa terdapat 39 objek wisata di Kabupaten Bandung Barat yang terdiri atas 26 objek wisata alam, 10 objek wisata budaya, dan 3 objek wisata khusus dengan total luas keseluruhan mencapai 4772,9 Ha, yang mana objek wisata alam merupakan objek wisata terbanyak di kabupaten tersebut. Objek wisata alam yang telah berkembang dan dikenal di pasar pariwisata adalah Orchid 
Forest Cikole, Punclut, Terminal Grafika, The Lodge Maribaya, Dusun Bambu, dan lain-lain ${ }^{1}$. Menurut data Dinas Pariwisata dan Kebudayaan Provinsi Jawa Barat, pada tahun 2016 jumlah wisatawan mancanegara dan wisatawan nusantara yang berkunjung ke objek wisata Kabupaten Bandung Barat sebesar 278.027 dan 1.289 .657 pengunjung dengan jumlah total pengunjung sebanyak $1.567 .684^{2}$. Selanjutnya pada tahun 2018, sekretaris Disparbud Kabupaten Bandung Barat mengatakan bahwa kunjungan wisatawan ke Kabupaten Bandung Barat mengalami peningkatan sebesar $40 \%$ dengan jumlah angka kunjungan terdiri atas 33.608 wisatawan mancanegara dan 5.814.070 wisatawan nusantara. ${ }^{3}$

Salah satu kampung di Kabupaten Bandung Barat yang telah menjadikan kampungnya sebagai kawasan agrowisata adalah Kampung Pasirangling yang terletak di Desa Sunten Jaya, Lembang, Kabupaten Bandung Barat. Potensi unggulan di Kampung Pasirangling yang

\footnotetext{
${ }^{1}$ https://www.wisatabdg.com/2019/03/inilahdata-kunjungan-wisatawan-ke.html [Diakses pada 13 November 2020] jumlah-kunjungan-wisatawan-ke-objek-wisatamenurut.html [Diakses pada 13 November 2020] ${ }^{3} \mathrm{https}$ ://www.javanews.tv/read/1902/kunjunganwisatawan-kabupaten-bandung-barat-naik-40persen [Diakses pada 13 November 2020]
}

dapat dikembangkan sebagai objek agrowisata antara lain adalah lokasinya yang berbatasan langsung dengan hutan sehingga terdapat pepohonan dan mata air yang membantu berjalannya integrasi antara tani dan ternak. Hal ini menjadikan agrowisata Kampung Pasirangling memiliki produk pertanian sendiri yang diolah oleh sebagian warganya diantaranya adalah pupuk feses sapi, biji kopi kemasan, permen karamel, dan minuman honje.

Berdasarkan uraian-uraian tersebut, maka tujuan dari penelitian ini adalah: 1) Mendeskripsikan karakteristik pengunjung agrowisata Kampung Pasirangling; dan 2) Mendeskripsikan perilaku berkunjung dari pengunjung agrowisata Kampung Pasirangling.

\section{METODE PENELITIAN}

\section{Objek dan Tempat Penelitian}

Objek yang diteliti adalah karakteristik dan perilaku berkunjung dari pengunjung. Penelitian ini dilakukan di agrowisata Kampung Pasirangling, Desa Sunten Jaya, Kecamatan Lembang, Kabupaten Bandung Barat.

\section{Desain Penelitian}

Penelitian ini menggunakan desain penelitian gabungam kuantitatif dan 
kualitatif. Metode penelitian yang digunakan adalah metode penelitian survei dengan instrumen penelitian berupa kuesioner terbuka dan wawancara mendalam.

\section{Variabel Penelitian}

1) Karakteristik Pengunjung

Karakteristik pengunjung meliputi:

a. Jenis kelamin, merupakan sifat jasmani dan rohani yang membagi makhluk hidup dalam dua kategori, yaitu pria dan wanita.

b. Usia, merupakan lamanya keberadaan seseorang diukur dalam satuan tahun.

c. Tingkat pendidikan formal, merupakan tingkat pendidikan formal responden yang meliputi SD, SMP, SMA, dan perguruan tinggi.

d. Pekerjaan, merupakan kegiatan sehari-hari yang dilakukan individu untuk memperoleh pendapatan yang terdiri atas pekerjaan utama dan pekerjaan sampingan.

e. Domisili, yaitu tempat kediaman yang sah dan resmi dari konsumen.

2) Perilaku Pengunjung agrowisata Kampung Pasirangling a. Perolehan informasi objek wisata, yaitu dari mana pengunjung mendapatkan informasi mengenai objek wisata.

b. Jumlah kunjungan, yaitu berapa kali wisatawan melakukan kunjungan pada kawasan agrowisata Kampung Pasirangling.

c. Rekan kunjungan, merupakan orang yang menemani pengunjung saat berkunjung ke objek wisata.

d. Alasan memilih tujuan wisata, merupakan latar belakang wisatawan memilih tempat wisata.

e. Kegiatan kunjungan, yaitu kegiatan yang dilakukan saat melakukan kunjungan ke kawasan agrowisata

Kampung Pasirangling.

f. Waktu berkunjung, yaitu jam berkunjung ke objek wisata.

g. Transportasi, yaitu kendaraan yang digunakan pengunjung untuk menuju objek wisata.

h. Wahana yang diketahui, merupakan jenis-jenis wahana yang diketahui pengunjung saat mengunjung objek wisata.

i. Wahana yang paling menarik, yaitu wahana yang dianggap 
pengunjung sebagai wahana yang paling menarik.

\section{Jenis dan Sumber Data}

Jenis data pada penelitian ini meliputi data primer dan data sekunder. Data primer berasal dari responden maupun informan yang berada pada tempat penelitian. Responden diambil secara accidental terhadap 15 pengunjung agrowisata Kampung Pasirangling yang bersedia untuk diwawancarai. Selain itu terdapat 6 responden dari masyarakat yang diambil secara purposive berdasarkan peran yang mereka miliki dalam mengelola berjalannya agrowisata. Sementara data sekunder yang digunakan dalam penelitian ini bersumber dari jurnal, buku, penelitian terdahulu, studi pustaka dan dokumentasi.

\section{Rancangan Analisis Data}

Pada penelitian ini, data dianalisis menggunakan statistika deskriptif berupa ukuran-ukuran gejala pusat dan dispersi, beberapa jenis grafik serta tabel distribusi frekuensi. Kemudian hasil analisis deskriptif tersebut dipadukan dengan data lainnya yang diperoleh dari catatancatatan lapangan hasil wawancara, observasi, dokumentasi serta data sekunder.

\section{HASIL DAN PEMBAHASAN}

Karakteristik Pengunjung dan Masyarakat Agrowisata Kampung Pasirangling

1. Jenis Kelamin

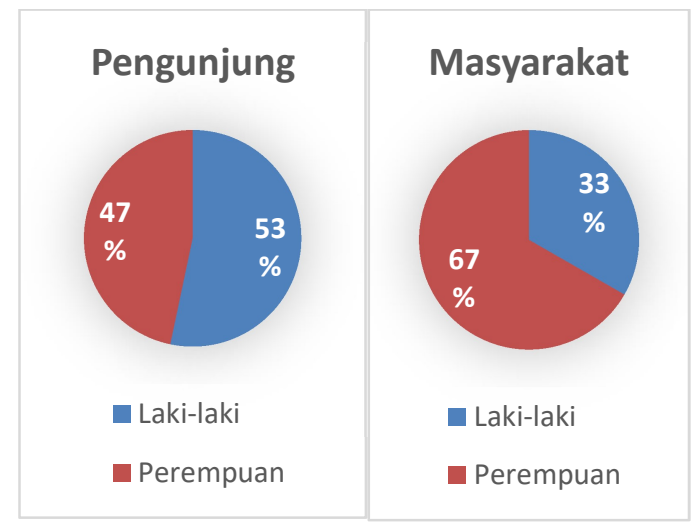

Gambar 1. Diagram lingkaran Jenis Kelamin Pengunjung dan Masyarakat Agrowisata Kampung Pasirangling

Gambar 1 menunjukkan bahwa pengunjung agrowisata Kampung Pasirangling hampir setara jumlahnya antara laki-laki dan perempuan, namun masih sedikit lebih banyak laki-laki sebesar 53\%. Hal tersebut sesuai dengan yang disampaikan pengelola bahwa mayoritas pengunjung yang datang ke Kampung Pasirangling adalah mahasiswa pecinta alam yang didominasi oleh lakilaki.

Berbeda halnya dengan responden masyarakat yang didominasi oleh perempuan sebanyak $67 \%$. Hal tersebut karena kebanyakan laki-laki bekerja di 
lahan sedangkan perempuan atau ibu-ibu bekerja menjaga warung, menjual makanan, sehingga lebih mudah dijangkau dan bersedia diwawancarai.

\section{Usia}

Dilihat dari segi usia, responden masyarakat sebagian besar merupakan lansia dengan rentang usia 46-65 tahun sedangkan responden pengunjung didominasi oleh remaja dalam rentang usia 17-25 tahun. Rentang usia ini merupakan usia produktif (Deaniera dkk. 2020).

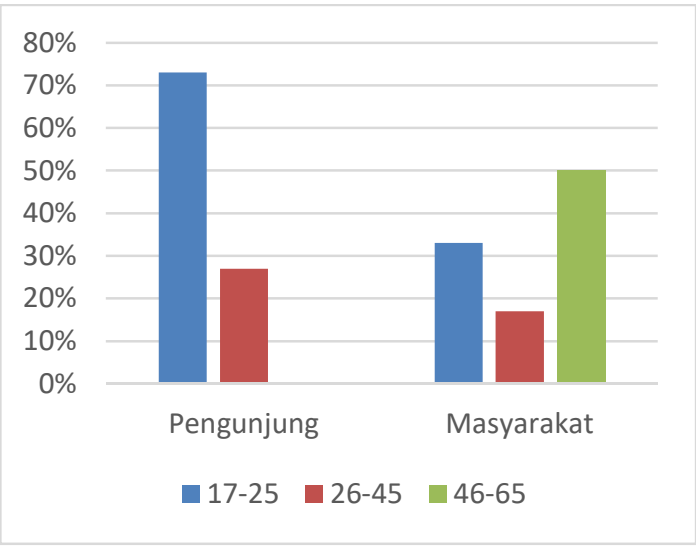

Gambar 2. Diagram lingkaran Usia Pengunjung dan Masyarakat Agrowisata Kampung Pasirangling

Berdasarkan hasil wawancara, banyaknya pengunjung remaja yang berstatus mahasiswa dikarenakan kunjungan yang dilakukan merupakan kunjungan oleh himpunan dan perhimpunan mahasiswa serta penggiat alam yang berada di sebuah perguruan tinggi. Pendapat yang sama juga dikatakan oleh Kang Aji selaku pengelola yang mengatakan:

"Pengunjung yang datang kesini biasanya ramai-ramai karena datangnya bersama teman-teman satu kegiatan di kampus. Selain itu, banyak juga penggiat alam dari kampus-kampus yang ke sini karena katanya cocok sebagai destinasi camping dan belajar di alam bebas. "4

Objek wisata yang disediakan di Agrowisata Kampung Pasirangling sangat sesuai dengan pengunjung yang sebagian besar merupakan mahasiswa penggiat alam. Berbeda halnya dengan salah satu penelitian yang dilakukan oleh Brahmanto dkk. (2018) di Kampung Tulip menunjukkan bahwa segementasi pasar yang ditentukan kurang sesuai dengan objek wisata yang disediakan. Hal tersebut diperjelas oleh salah satu pengelola yang mengatakan bahwa segmentasi pasar agrowisata Kampung Pasirangling ditujukan untuk kalangan anak-anak, namun pada kenyataannya fasilitas dan objek wisata yang disediakan lebih tepat ditujukan untuk kalangan dewasa.

3. Tingkat Pendidikan

Berdasarkan Gambar 3 diketahui bahwa mayoritas pengunjung agrowisata Kampung Pasirangling memiliki tingkat

\footnotetext{
${ }^{4}$ Kang Aji, Pengelola (Ketua Karang Taruna), Wawancara, 24/01/2020.
} 
pendidikan SMA sebesar $60 \%$ dengan sisanya adalah sarjana. Hal tersebut sesuai bahwa kebanyakan pengunjung yang datang adalah mahasiswa. Sedangkan untuk masyarakat Kampung Pasirangling sendiri memiliki tingkat pendidikan yang beragam, dari mulai SD, SMP, dan SMA dengan perbandingan yang sama. Berdasarkan Wati dkk. (2020), tingkat pendidikan merupakan salah satu faktor yang berkorelasi signifikan dengan tingkat produktivitas tertama dalam penerapan teknologi.

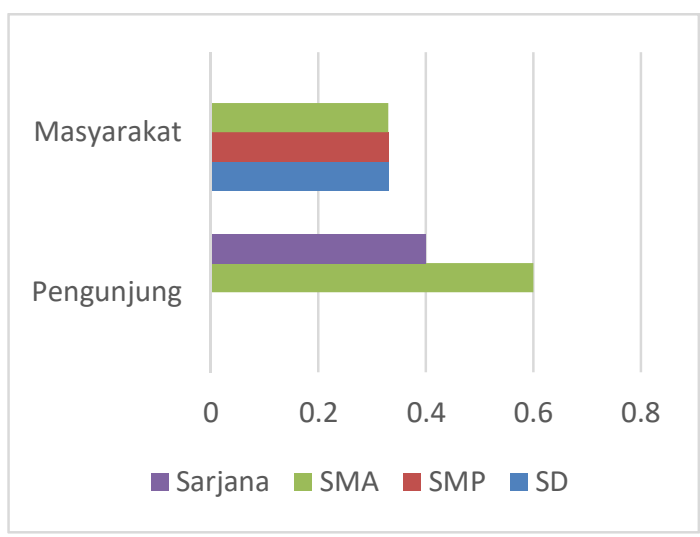

Gambar 3. Diagram lingkaran Tingkat Pendidikan Pengunjung dan Masyarakat Agrowisata Kampung Pasirangling

\section{Pekerjaan}

Pengunjung yang datang ke agrowisata Kampung Pasirangling berasal dari latar belakang pekerjaan yang beragam, dari mulai mahasiswa, wiraswasta, pegawai swasta, dan lainlain. Berdasarkan Gambar 4 diketahui bahwa pengunjung didominasi oleh mahasiswa dengan persentase $47 \%$. Sama halnya dengan pengunjung, responden masyarakat Kampung Pasirangling juga memiliki pekerjaan yang beragam namun yang paling banyak adalah pedagang dan pelajar yang presentasenya masingmasing $33 \%$.

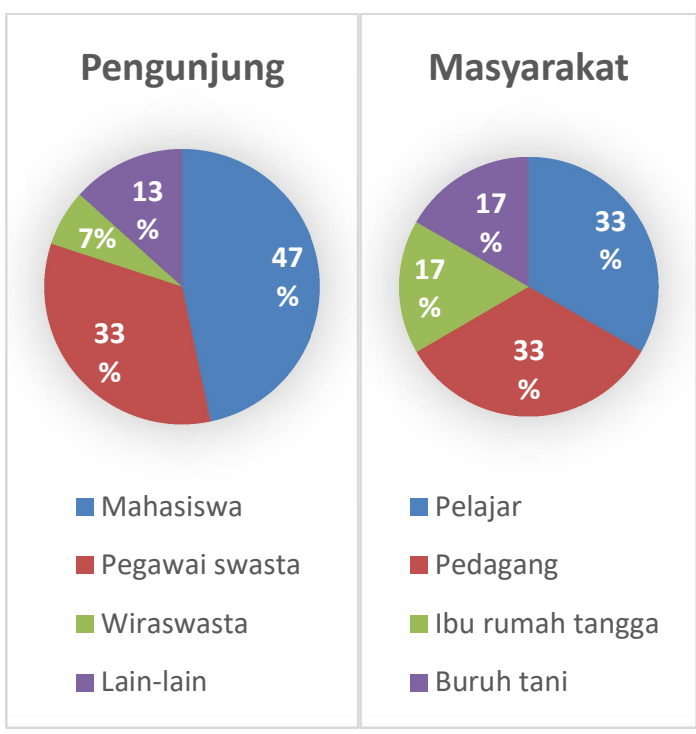

Gambar 4. Diagram lingkaran Pekerjaan Pengunjung dan Masyarakat Agrowisata Kampung Pasirangling

\section{Domisili}

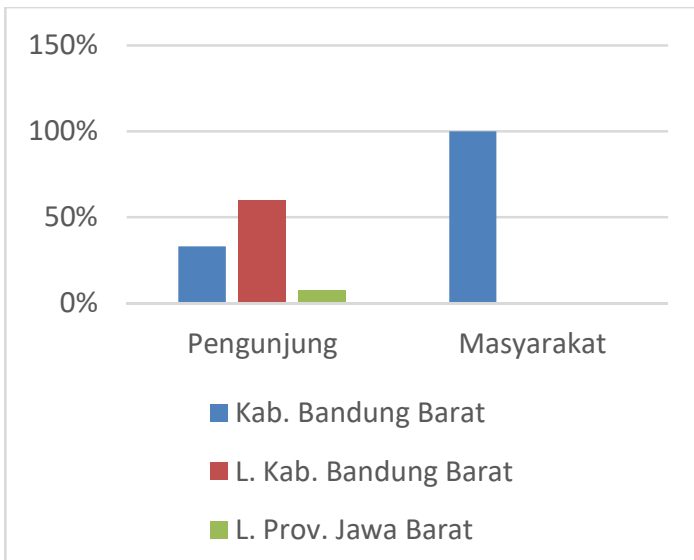

Gambar 5. Diagram lingkaran Domisili Pengunjung dan Masyarakat Agrowisata Kampung Pasirangling

Responden pengunjung yang datang ke agrowisata Kampung 
Pasirangling paling banyak berasal dari luar Kabupaten Bandung Barat yaitu sebesar $60 \%$. Berdasarkan hasil wawancara di lapangan, mereka berasal atau berdomisili di Kota Bandung, Subang, Purwakarta, dan Cimahi yang sengaja datang untuk berkunjung dan juga belajar. Berbeda halnya dengan responden masyarakat, semuanya berdomisili tetap di Kampung Pasirangling yang berada di Kabupaten Bandung Barat.

\section{Perilaku Berkunjung dari Pengunjung}

\section{Agrowisata Kampung Pasirangling}

Berdasarkan hasil analisis mengenai perilaku berkunjung dari pengunjung agrowisata Kampung Pasirangling (Tabel 2), menunjukkan bahwa responden pengunjung memperoleh informasi mengenai agrowisata Kampung Pasirangling paling banyak melalui teman. Pengunjung yang datang ke agrowisata Kampung Pasirangling kebanyakan bukan merupakan kunjungan pertama, hanya sebagian pengunjung saja (20\%) yang pertama kali berkunjung ke Kampung Pasirangling.
Tabel 2. Deskripsi Perilaku Berkunjung dari Pengunjung Agrowisata Kampung Pasirangling

\begin{tabular}{|c|c|c|c|}
\hline No & Perilaku & $\begin{array}{l}\text { Jumlah } \\
\text { (orang) }\end{array}$ & $\begin{array}{c}\text { Persentase } \\
(\%)\end{array}$ \\
\hline \multirow[t]{5}{*}{1} & Perolehan Informasi & & \\
\hline & a. Teman & 8 & 53,3 \\
\hline & b. Keluarga & 1 & 6,6 \\
\hline & c. Internet & 3 & 20 \\
\hline & d. Universitas & 3 & 20 \\
\hline \multirow[t]{5}{*}{2} & Jumlah Kunjungan & & \\
\hline & a. Satu kali & 3 & 20 \\
\hline & b. Dua kali & 4 & 26,6 \\
\hline & c. Tiga kali & 4 & 26,6 \\
\hline & d. $>$ tiga kali & 4 & 26,6 \\
\hline \multirow[t]{6}{*}{3} & $\begin{array}{l}\text { Dengan siapa } \\
\text { melakukan kunjungan }\end{array}$ & & \\
\hline & a. Keluarga & - & - \\
\hline & b. Teman-teman & 6 & 40 \\
\hline & c. Rombongan & 8 & 53,3 \\
\hline & d. Pasangan & 1 & 6,6 \\
\hline & e. Sendiri & - & - \\
\hline \multirow[t]{6}{*}{4} & Alasan berkunjung & & \\
\hline & a. Keindaha tempat & 7 & 46,6 \\
\hline & $\begin{array}{l}\text { b. Banyak objek } \\
\text { wisata }\end{array}$ & - & - \\
\hline & $\begin{array}{l}\text { c. Sarana dan } \\
\text { prasarana yang } \\
\text { ditawarkan }\end{array}$ & 5 & 33,3 \\
\hline & d. Harga & 2 & 13,3 \\
\hline & e. Lainnya & 1 & 6,6 \\
\hline \multirow[t]{4}{*}{5} & $\begin{array}{l}\text { Jenis kegiatan yang } \\
\text { dilakukan }\end{array}$ & & \\
\hline & a. Rekreasi/liburan & 6 & 40 \\
\hline & b. Urusan pekerjaan & - & - \\
\hline & c. Pendidikan & 9 & 60 \\
\hline \multirow[t]{4}{*}{6} & Waktu berkunjung & & \\
\hline & a. Pagi hari & 9 & 60 \\
\hline & b. Siang hari & 3 & 20 \\
\hline & c. Sore hari & 3 & 20 \\
\hline \multirow[t]{5}{*}{7} & $\begin{array}{l}\text { Alat transportasi yang } \\
\text { digunakan }\end{array}$ & & \\
\hline & a. Sepeda motor & 8 & 53,3 \\
\hline & b. Mobil & 5 & 33,3 \\
\hline & c. Bus wisata & - & - \\
\hline & d. Lainnya & 2 & 13,3 \\
\hline \multirow[t]{5}{*}{8} & $\begin{array}{l}\text { Wahana yang paling } \\
\text { menarik }\end{array}$ & & \\
\hline & a. Bumi perkemahan & 8 & 53,3 \\
\hline & b. Hutan lindung & 3 & 20 \\
\hline & $\begin{array}{l}\text { c. Wisata pupuk feses } \\
\text { sapi }\end{array}$ & 2 & 13,3 \\
\hline & $\begin{array}{l}\text { d. Wisata pohon } \\
\text { tegakan }\end{array}$ & 2 & 13,3 \\
\hline
\end{tabular}


Beberapa pengunjung yang sudah lebih dari satu kali berkunjung, mengungkapkan bahwa agrowisata Kampung Pasirangling merupakan tempat yang cocok untuk berkemah, belajar, dan beristirahat dari keramaian kota karena keindahan dan kenyamanan yang disuguhkan sehingga terbentuk rasa ingin berkunjung kembali. Hal tersebut juga didukung oleh hasil wawancara yang menyebutkan bahwa sebanyak 46,6\% pengunjung memilih agrowisata Kampung Pasirangling dikarenakan keindahan, dengan tujuan yang paling utama adalah mendapatkan pendidikan kemudian berlibur. Suasana yang nyaman di agrowisata memang merupakan salah satu faktor penting untuk menarik pengujung. Seperti dinyatakan oleh Saefudin dkk. (2020) bahwa suasana yang nyaman dapat membuat pengunjung betah dan ingin kembali mengujungi. Pengunjung kebanyakan datang bersama rombongan maupun teman-teman.

Pengunjung umumnya paling banyak datang di pagi hari dan mulai beraktivitas hingga esok hari. Hal tersebut dikarenakan kebanyakan pengunjung datang dengan tujuan untuk kegiatan berkemah. Alat transportasi yang digunakan mayoritas sepeda motor karena mengingat kondisi jalan yang menanjak dan tidak terlalu lebar di agrowisata Kampung Pasirangling. Salah satu pengunjung yang menggunakan sepeda motor mengatakan:

"Akses dan jalan menuju ke Kampung Pasirangling sudah bagus tapi saat sampai depan gapura kampung, tanjakannya sangat curam dan jalannya juga kecil sehingga lebih nyaman diakses menggunakan motor. Kalau menggunakan mobil sepertinya masih agak sempit apalagi kalau ada mobil lain dari arah yang berlawanan.,"5

Agrowisata Kampung Pasirangling sendiri memiliki cukup banyak objek wisata atau wahana untuk dinikmati pengunjung di antaranya kawasan bumi perkemahan, hutan lindung, wisata pupuk feses sapi, dan wisata pohon tegakan. Menurut Rasmikayati dkk. (2020) fasilitas atau wahana yang beragam merupakan salah satu aspek penting dalam menarik minat pengunjung untuk datang berkunjung. Berdasarkan hasil wawancara menunjukkan bahwa seluruh informan pengunjung mengetahui adanya bumi perkemahan di Kampung Pasirangling dan objek wisata yang masih belum banyak diketahui adalah wisata pupuk feses sapi. Pupuk kotoran sapi ini merupakan pupuk organik yang sangat

\footnotetext{
${ }^{5}$ Siti Aulia, Pengunjung, Wawancara, 24/01/2020.
} 
baik untuk pertanian. Merujuk kepada Muchtar (2020) pemberian pupuk kotoran sapi sebanyak 15 ton per hektar dapat mengoptimalkan produksi tanaman buncis. Kemudian merujuk pada Rasmikayati dkk. (2020) bahwa kesadaran masyarakat dalam mengkonsumsi produk pertanian organik berkorelasi nyata dengan tingkat pendidikan mereka, sehingga semakin tinggi tingkat pendidikannya maka kesadaran akan konsumsi produk organik akan semakin tinggi.

Pengelola menjelaskan bahwa agrowisata Kampung Pasirangling memang dikenal dengan kawasan bumi perkemahannya sehingga banyak yang berkunjung untuk melakukan kegiatan perkemahan sedangkan wahana lainnya pada umumnya harus dikenalkan terlebih dahulu kepada pengunjung saat berada di lokasi wisata. Tingginya minat terhadap bumi perkemahan di kawasan Kampung Pasirangling juga dikarenakan kebanyakan pengunjung yang datang merupakan anggota dari organisasi pecinta alam yang memanfaatkan alam untuk rekreasi maupun mendapatkan pendidikan.

Promosi dapat meningkatkan jumlah pengunjung secara signifikan (Rasmikayati dkk. 2020). Promosi yang dilakukan pengelola agrowisata Kampung Pasirangling untuk menarik minat pengunjung adalah promosi langsung antar mulut atau biasa dikenal dengan word of mouth. Bumi perkemahan merupakan objek yang bersih dan terawat sehingga ketika ada salah satu organisasi pecinta alam yang datang berkunjung dan melakukan kegiatan berkemah, setelahnya mereka akan menginformasikan kepada temantemannya. Hal tersebut sesuai dengan pendapat salah satu pengunjung yang sedang melakukan kegiatan berkemah yang mengatakan,

"Cocok banget buat refreshing dari keramaian kota karena masih sangat asri dan juga memiliki pemandangan yang indah. Selain dari itu, pengelolanya juga sangat ramah dan sering menemani saat kegiatan sehingga kami merasa sangat dijamu dan nyaman. "6

Pengunjung yang menggunakan area bumi perkemahan tertib dan bersedia membayar Rp 10.000/orang serta mengikuti arahan khususnya untuk menjaga kebersihan lingkungan. Kebersihan dan keindahan selalu terjaga agar pengunjung yang datang merasa puas dan berkeinginan untuk berkunjung kembali. Selain bumi perkemahan,

\footnotetext{
${ }^{6}$ Dendi Aditya, Pengunjung, Wawancara, 24/01/2020.
} 
wahana yang paling banyak diketahui adalah hutan lindung dan pohon tegakan. Wahana atau objek wisata ini berada di area bumi perkemahan, sehingga pengunjung yang melakukan kegiatan berkemah pasti akan menikmati area hutan lindung dan pohon tegakan. Pengunjung yang datang mayoritas bersedia menanam dan membayar harga bibit untuk ditanam dengan kisaran harga Rp 2.500 - Rp 5.000 sebagai perwujudan peduli lingkungan.

Objek wisata lain yang bisa dikunjungi oleh pengunjung adalah agrowisata pupuk feses sapi. Agrowisata ini masih sedikit peminatnya namun pengelola terus berupaya mempromosikan kepada pengunjung yang datang. Sejauh ini pengunjung yang datang ke wisata pupuk feses sapi tergolong tertib dan bersedia membayar $\mathrm{Rp} \quad 5.000$ untuk mengikuti pelatihan pembuatan pupuk organik. Merujuk kepada Rasmikayati dkk. (2020), jumlah kebutuhan produk pertanian organik saat ini masih belum bisa diimbamgi oleh produksinya, sehingga agrowisata pupuk organik ini diharapkan dapat meningkatkan pengetahuan dan minat masyarakat dalam bertani secara organik yang pada akhirnya diharapkan dapat memacu produksi produk pertanian organik di Indonesia. kemudian dari segi manajemen kunjungan, pengelola mengaku bahwa dengan sistem kuota yang diberlakukan bagi pengunjung yang datang membuat kawasan agrowisata Kampung Pasirangling menjadi lebih tertib dan nyaman sehingga memberikan kepuasan bagi pengunjung. Peningkatan fasilitas dan insfrastruktur di kawasan agrowisata ini memang sangat perlu dilakukan agar performanya semakin meningkat. Hal tersebut sejalan dengan Amridha dkk. (2020) yang mengungkapkan bahwa peningkatan fasilitas berpengaruh signifikan terhadap performa suatu perusahaan.

\section{KESIMPULAN}

Agrowisata Kampung Pasirangling memiliki jumlah pengunjung yang hampir setara antara wisatawan laki-laki dan perempuan. Pengunjung didominasi oleh remaja dalam rentang usia 17-25 tahun yang sebagian besarnya merupakan mahasiswa. Banyaknya pengunjung remaja yang berstatus mahasiswa dikarenakan kunjungan yang dilakukan merupakan kunjungan oleh himpunan dan perhimpunan mahasiswa serta penggiat alam yang berasal dari sebuah perguruan tinggi di luar Kabupaten Bandung Barat. 
Dari segi perilaku, pengunjung paling banyak memperoleh informasi mengenai Kampung Pasirangling dari teman lalu pengunjung yang merasa puas mempromosikannya kepada temantemannya yang lain lalu bersama-sama melakukan kunjungan. Sebagian besar kunjungan yang dilakukan pengunjung Agrowisata Kampung Pasirangling bukan merupakan kunjungan pertama. Mereka melakukan kunjungan untuk kegiatan yang berkaitan dengan wisata alam terutama berkemah. Ada juga yang bertujuan untuk pendidikan agrowisata seperti agrowisata hutan lindung, pupuk feses sapi dan pohon tegakan namun persentasenya masih kecil.

\section{DAFTAR PUSTAKA}

Amridha, Y., Heryanto, M. A., Saefudin, B. R., \& Awaliyah, F. (2020). The Analysis of The Employee's Job Satisfaction and Performance In Private Agricultural Company. Mahatani: Jurnal Agribisnis (Agribusiness and Agricultural Economics Journal), 2(2).

Brahmanto, E., Musafa, M., \& Suryana, S. (2018). Upaya Mewujudkan Wisata Edukasi Di Kampung Tulip Bandung. Jurnal Abdimas BSI: Jurnal Pengabdian Kepada Masyarakat, 1(1).

Deaniera, A. N., Rasmikayati, E., Saefudin, B. R., Supyandi, D., \& Sukayat, Y. (2020). Studi Komparatif Proses Bisnis Usaha Jigana Coffee Shop Dan Kedai
Kopi Inspirasi Cibinong, Kabupaten Bogor.

Machdalena, S., Dewi, A. P., \& Soemantri, Y. S. (2018). The Lodge Maribaya Sebagai Salah Satu Pilihan Destinasi Ekowisata Kabupaten Bandung Barat. Jurnal Pariwisata Terapan, 2(2), 96-107.

Muchtar, J. (2020). Variasi Pemberian Pupuk Organik Kotoran Sapi dan Ayam terhadap Tanaman Buncis sebagai Upaya Meningkatkan Produktivitas Usahatani Buncis. Agritekh (Jurnal Agribisnis dan Teknologi Pangan), 1(01), 72-95.

Rasmikayati, E., Afriyanti, S., \& Saefudin, B. R. (2020). Keragaan, Potensi dan Kendala pada Usaha Kedai Kopi Di Jatinangor: Kasus pada Belike Coffee Shop dan Balad Coffee Works. Agritekh (Jurnal Agribisnis dan Teknologi Pangan), 1(01), 26-45.

Rasmikayati, E., Deaniera, A. N., Supyandi, D., Sukayat, Y., \& Saefudin, B. R. (2020). Analisis Perilaku Konsumen: Pola Pembelian Kopi Serta Preferensi, Kepuasan Dan Loyalitas Konsumen Kedai Kopi. Mimbar Agribisnis: Jurnal Pemikiran Masyarakat Ilmiah Berwawasan Agribisnis, 6(2), 969-984.

Rasmikayati, E., Djuwendah, E., Saefudin, B. R., Syamsiyah, N., \& Ridhatillah, A. (2020). Kajian Pemasaran Relasional Bayam Jepang (Horenso) Organik Di Inagreen Farm, Dilema Antara Harapan Dan Kenyataan. Mimbar Agribisnis: Jurnal Pemikiran Masyarakat Ilmiah Berwawasan Agribisnis, 6(1), 365-376.

Rasmikayati, E., Shafira, N. A., Fauziah, Y. D., Ishmah, H. A. N., Saefudin, B. R., \& Utami, K. (2020). Keterkaitan antara Karakteristik Konsumen dengan Tingkat 
Kepuasan Mereka dalam Melakukan Pembelian Sayuran Organik. Agricore: Jurnal Agribisnis dan Sosial Ekonomi Pertanian Unpad, 5(1).

Rudita, I. K. P., \& Sitorus, S. R. (2012). Potensi obyek wisata dan keterpaduannya dalam pengembangan kawasan Agropolitan Payangan, Kabupaten Gianyar, Provinsi Bali. Jurnal Lanskap Indonesia, 4(1).

Saefudin, B. R., Deanier, A. N., \& Rasmikayati, E. (2020). Kajian Pembandingan Preferensi Konsumen pada Dua Kedai Kopi di Cibinong, Kabupaten Bogor. AGROVITAL: Jurnal Ilmu Pertanian, 5(1), 39-46.
Sukriah, E. (2014). Pariwisata Sebagai Sektor Unggulan Kota Bandung. Jurnal Manajemen Resort dan Leisure, 11(1), 65-74.

Wati, F., Rasmikayati, E., \& Saefudin, B. R. (2020). Analisis Hubungan Karakteristik Anggota Kelompok Tani dengan Penerapan Teknologi Off Season pada Kegiatan Usahatani Mangga di Kecamatan Sedong, Kabupaten Cirebon, Jawa Barat. Jurnal Ekonomi Pertanian dan Agribisnis, 4(4), 715-727. 